Ropartz, P. Demonstration of an increase of locomotor activity of groups of female mice to the od or of a group of strange males. C. R. Hebd. Seances Ser. D Sci. Natur., 1968, 267, $9.341-2.343$.

Scott, J. W., \& Pafaff, D. W. Behavioral and electrophysiological responses of female mice to male urine odors. Physiology and Behavior, 1970, 5, 407-411.

Stern, J. J. Responses of male rats to sex odors. Physiology \&
Behavior, 1970, 5, 519-524.

Vandenbergh, J. G. Male odor accelerates female sexual maturation in mice. Endocrinology, 1969, 84, 658-660.

Whitten, W. K. Pheromones and mammalian reproduction. In. E. McLaren (Ed.), Advances in reproductive physiology. Vol. I, New York, Academic, 1966.

\title{
Eyewitness testimony: The influence of the wording of a question
}

\author{
ELIZABETH F. LOFTUS \\ University of Washington, Seattle, Washington 98195 \\ and \\ GUIDO ZANNI \\ New School for Social Research, New York, New York 10011
}

\begin{abstract}
Two experiments are reported in which subjects viewed a film of an automobile accident and then answered questions about events occurring in the film. Relative to questions containing an indefinite article (e.g., Did you see $a$ broken headlight?), questions which contained a definite article (e.g., Did you see the broken headlight?) produced (1) fewer uncertain or "I don't know" responses, and (2) more "recognition" of events that never, in fact, occurred. The results, which are consistent with the view that questions asked subsequent to an event can cause a reconstruction in one's memory of that event, have important implications for courtroom practices and eyewitness investigations.
\end{abstract}

An automobile accident is a highly complex and sudden event often lasting only a few seconds. Is our perception, recollection, and verbalization of such an incident an identical copy of the original event? Most researchers in the field of human memory would agree that the answer to this question is "no." There are numerous ways to influence (and often distort drastically) the recollections of a witness. One relatively easy way is to vary the method by which the recollection is elicited or to vary the form in which questions are asked about the recollection.

Much of the research in this area has indicated that when people are forced to answer specific questions, rather than to report freely, their reports are more complete but less accurate (Cady, 1924; Gardner, 1933; Marquis, Marshall \& Oskamp, 1972; Marston, 1924; Whipple, 1909). Furthermore, the accuracy of an answer to a specific question can be noticeably influenced by the wording of the question itself. By changing one or two words in a question, clear-cut variations have been shown to appear in as diverse areas as a subject's report of hypnotic experiences (Barber, 1969) and in his estimates of the speed of a moving vehicle (Loftus \&

This research was supported by the Urban Mass Transportation Administration, Department of Transportation, Grant No. WA-11-0004. Requests for reprints should be sent to Elizabeth F. Loftus, Psychology Department, University of Washington, Seattle, Washington 98195.
Palmer, in press). The wording of a question is such an important matter, that a recent book intended to help potential questionnaire designers (Oppenheim, 1966) devotes an entire chapter to the topic of question wording.

The present research demonstrates the influence of very small changes in the wording of a question in a situation in which subjects viewed a film of an automobile accident and then answered questions about events that did and did not occur in the film. For some of the questions, the English article the (the definite article) was used, as in "Did you see the broken headlight?" For other questions the article $a$ (the nondefinite or indefinite article) was used resulting in questions like "Did you see a broken headlight?" Previous research on the definite and indefinite article has been equivocal as to whether there is a difference in influence between the two. Muscio (1915) concluded that the more reliable form of question was one that did not use the definite article, whereas Burtt (1931) reported that $a$ and the are about equally suggestive.

What is the difference between the and $a$, and why should use of these articles produce differential behavior on the part of eyewitnesses? On this topic, a number of psychologists have recently had something to say (e.g., Anderson \& Bower, 1973; Brown, 1973; Chafe, 1972; Maratsos, 1971; Osgood, 1971); most have made the 
point that if a speaker has already seen a particular item, and assumes his listener is also familiar with it, he will use the article the. For example, when a young man wants to borrow the family car, he says "Can I have the family car tonight?" These notions have already been successfully embodied into an elaborate model of human memory called HAM (Anderson \& Bower, 1973); when HAM sees a noun preceded by the it looks for the referent of that term in its memory. In contrast, when HAM sees a noun preceded by $a$ it assumes that a new member of the noun class is being introduced into its memory.

To return to the example of accidents and the or $a$ broken headlight, consider first the question, "Did you see a broken headlight?" Two questions are implicitly being asked here: (1) Was there a broken headlight? and (2) if there was, did you see it? If a subject decides that the answer to Question 1 is "yes," he can then ask himself Question 2, and he should be fairly certain of his response. The problem that arises for a subject is that filmed accidents occur in the space of seconds making it nearly impossible to be certain of Question 1, and making it likely that the subject will respond "don't know" much of the time.

In contrast, the second question, "Did you see the broken headlight?" can be translated into the nearly equivalent, "There was a broken headlight. Did you happen to see it?" Thus, a subject who is interrogated with the definite article does not need to answer Question 1. Effectively, the answer is "yes." He need only answer Question 2, and, as was the case with the indefinite article, at this point he can be fairly certain about his response. According to this analysis, fewer "don't know" responses would be expected. Furthermore, if a subject's recollections tend to conform, for some reason, to what he believes actually did occur, then the definite article may lead to a greater "recognition" of events, even when they never in fact occurred.

\section{EXPERIMENT I}

\section{Method}

One hundred graduate students participated in this experiment, in groups of various sizes. All subjects were told that they were participating in an experiment on memory and that they would be shown a short film followed by a questionnaire. The content of the film was not mentioned.

The film itself depicted a multiple car accident. Specifically, a car makes a right hand turn to enter the main stream of traffic; this turn causes the cars in the oncoming traffic to stop suddenly, causing a five car bumper to bumper collision. The total time of the film is less than $1 \mathrm{~min}$, and the accident itself occurs within a 4-sec period.

At the end of the film, the subjects received a questionnaire asking them to first "give an account of the accident you have just seen." When they had completed their accounts, a series of specific questions was asked. Six critical questions were embedded in a list totaling 22 questions. Half the subjects received critical questions in the form, "Did you see $a$...?" and the other half of the subjects received them in the form, "Did you see the ...?" Three of the critical questions pertained to items present in the film and three to items not present. Subjects were urged to report only what they saw, and did so by checking "yes," "no," or "I don't know." Each subject received a different permutation of the questions.

\section{Results}

Table 1 presents the percentage of "yes," "no," and "I don't know" responses for both the "the" and "a" subjects. Whether an item was actually present or not, subjects interrogated with $a$ were over twice as likely to respond "I don't know." Subjects interrogated with the tended to commit themselves to a "yes" or "no" response.

Another aspect of these data are worthy of mention. First, when a subject is queried about an item that was not present in the film, "yes" responses are particularly interesting. A "yes" response indicated a subject reported that he saw something that was not, in fact, present. Using the indefinite article resulted in false "yes" responses $7 \%$ of the time. With the definite article, however, false "yes" responses occurred $15 \%$ of the time-over twice as often.

To test statistically for the difference between interrogation with $a$ and with the, a single score for each subject was generated. "Yes" responses were assigned a value of +1 , "I don't know" responses were assigned a value of 0 , and "No' responses were assigned a value of -1 . A subject's mean score, then, reflected his confidence that the items were present. The difference between the "confidence scores" for the $a$ and the subjects was significant by a Mann-Whitney U test, $\mathrm{z}=$ $2.98, \mathrm{p}<.01$.

To test for the difference between items which were and were not present, two mean scores for each subject were generated, one for items which were present and the other for items which were not. Again, "yes" responses received a value of +1 , "I don't know" responses a value of 0 , and "No" responses a value of -1 . As before, a subject's mean score for a particular type of item expressed his confidence that those items were present. Two Wilcoxon matched-pairs signed-ranks tests revealed that both the subjects who had been interrogated with $a$ and the subjects who had been interrogated with the were more confident about items that had been present, $\mathrm{z}=3.97, \mathrm{p}<.001$, and $\mathrm{z}=2.52$, $\mathrm{p}<.01$, respectively.

\section{EXPERIMENT II}

\section{Method}

In order to be sure that the results obtained were not peculiar to the film or subject population used in Experiment I, a second experiment was conducted. Experiment II was identical to Experiment $I$ in all respects except two. First, a different subject population was used; 60 people between the ages of 14 and 20 were recruited from a public library. Second, a different film was used. The film shown in a small room at the library, depicted a minor collision between a man who was backing out of a narrow space in a supermarket parking lot and a woman pedestrian who 
was carrying a large bag of groceries. The total time of the film was less than $4 \mathrm{~min}$, and the accident itself occurred with a 2 -sec period.

Subjects viewed the film and then answered a questionnaire. Six critical questions were embedded in a list of $22 ; 3$ pertained to items present in the film and 3 to items not present. The definite article was used for 30 subjects; the indefinite article for the other 30 .

\section{Results}

Table 1 presents the percentage of "yes," "no," and "I don't know" responses for both the "the" and "a" subjects. The effects of Experiment I are replicated. When an indefinite article was contained in a question about an item that was not present in the film, "yes" responses occurred $6 \%$ of the time. When the definite article was used, "yes" responses occurred $20 \%$ of the time. "I don't know" responses occurred, overall, more often when the indefinite article was used (47.5\% vs. $15.5 \%$ for the definite article).

\section{DISCUSSION}

The research reported here required subjects to view a film of a traffic accident and then to answer questions about the film. A major finding was that questions containing an indefinite article led to many more "I don't know" responses. The phrase "a broken headlight" could refer to any of a number of headlights which a subject might have seen. Since it is impossible to inspect all of the headlights carefully in the time allowed for viewing the accident, it is impossible to be sure that no headlight was broken. In this case, then, the subject must deal with uncertainty about whether a broken headlight actually existed at all, and a larger number of "uncertain" or "don't know" responses result. On the other hand, "Did you see the broken headlight?" more strongly implies the existence of a specific broken headlight, and the subject need not deal with the uncertainty about whether the broken headlight existed. This finding may also indicate that it is easier to be confident that you have not seen some specific item than to be confident that you have not seen any instance of a general class of items.

A second result is that questions containing a definite article resulted in a greater number of false recognitions ("recognition" of events that had never occurred). At least two explanations for this finding are possible. One is that the definite article produces a bias favoring a "yes" or "no" response; in other words, the changes a subject's criteria for how much objective evidence he needs to say "yes" or "no." The other is that the definite article leads a subject to infer that the object was in fact present, causing for some a reconstruction in their original memory for the event. While the present data cannot differentiate between response bias and reconstructive memory explanations, a recent study (Loftus \& Palmer, in press) does not indicate that questions asked subsequent to an event can cause a reconstruction in one's memory of that event. In that study subjects viewed films of automobile accidents and then answered questions about events occurring in the films. The question "About how fast were the cars going when they smashed into each other?" elicited a higher estimate of speed than "About how fast were the cars going when they hit each other?" Furthermore, on a retest 1 week later, those subjects who received the verb smashed were more likely to say "yes" to the question "Did you see any broken glass?" even though broken glass did not exist in the accident.

The implication of these results for courtroom examinations, police interrogations, and accident investigations is fairly clear
Table 1

Percentage of "Yes," "No," and “I don't know" Responses to Items that Were Present and Not Present in the Film

\begin{tabular}{lcccr}
\hline & \multicolumn{2}{c}{ Present } & & \multicolumn{2}{c}{ Not Present } \\
\cline { 2 - 3 } \cline { 5 - 5 } Response & "the" & "a" & "the" & "a" \\
\hline & \multicolumn{4}{c}{ Experiment I } \\
Yes & 17 & 20 & 15 & 7 \\
No & 60 & 29 & 72 & 55 \\
I don't know & 23 & 51 & 13 & 38 \\
& & Experiment II & \\
Yes & 18 & 15 & 20 & 6 \\
No & 62 & 28 & 69 & 56 \\
I don't know & 20 & 57 & 11 & 38 \\
\hline
\end{tabular}

cut. The main aim of interrogations conducted by attorneys before the court, for examıple, is to provide information about events which have actually taken place. Different forms of questions can be consciously used to elicit desired answers from a witness, and also to create a desired influence upon the jury. In the present research, the indefinite article elicited more false responses. Questions which either by form or content suggest to the witness the answer desired or "lead" him to that desired answer are called "leading questions' in the courtroom, and the existence of rules for excluding them (e.g., Supreme Court Reporter, 1973) is a dufinite recognition of their power of suggestion. While an attorney can seemingly easily "sense" when to object to a leading question asked by another attorney, the definition of leading is a long way from being precise. Any complete definition must eventually consider the subtle suggestibility that individual words can carry with them.

\section{REFERENCES}

Anderson, J. R., \& Bower, G. H. Human associative memory. Washington, D. C: V. H. Winston \& Sons, 1973.

Barber, T. X. Hypnosis: a scientific approach. New York: Van Nostrand Reinhold, 1969.

Brown, R. A first language: the early stages. Cambridge, Mass: Harvard University Press, 1973.

Burtt, H. Legal Psychology, 1931.

Cady, H. M. On the psychology of testimony. American Journal of Psychology, 1924, 35, 110-112.

Chafe, W. L. Discourse structure and human knowledge. In J. B. Carroll \& R. R. Freedle (Eds.), Language comprehension and the acquisition of knowledge. Washington, D. C: V. H. the acquisition of $k$.
Winston \& Sons, 1972 .

Gardner, D. S. The perception and memory of witnesses. Cornell Law Quarterly, 1933, 8, 391-409.

Loftus, E. F. \& Palmer, J. C. Reconstruction of automobile destruction: an example of the interaction between language and memory. Journal of Verbal Learning and Verbal Behavior, in press.

Maratsos, M. P. The use of definite and indefinite reference in young children. PhD dissertation, Harvard University, 1971.

Marquis, K. H., Marshall, J., Oskamp, S. Testimony validity as a function of question form, atmosphere, and item difficulty. Journal of Applied Social Psychology, 1972, 2, 167-186.

Marston, W. M. Studies in testimony. Journal of Criminal Law and Criminology, 1924, 15, 5-31.

Muscio, B. The influence of the form of question. British Journal of Psychology, 1915, 8, 351-389.

Oppenheim, A. N. Questionnaire design and attitude measurement. New York: Basic Books, Inc., 1966.

Osgood, C. E. Where do sentences come from? In D. D. Steinberg \& L. A. Jakobovits (Eds.), Semantics: An interdisciplinary reader in philosophy, linguistics, and psychology. Cambridge, England: Cambridge University Press, 1971.

Supreme Court Reporter, 1973, 3: Rules of Evidence for United States Courts and Magistrates.

Whipple, G. M. The observer as reporter: A survey of the psychology of testimony. Psychological Bulletin, 1909, 6 , 153-170.

(Received for publication October $71,1974$. 